\title{
Development of Extremely Large Area Light-emitting-diode-embedded Fabric and Investigation of Its Mechanical Properties
}

\author{
Seiichi Takamatsu, ${ }^{1 *}$ Takahiro Yamashita, ${ }^{2}$ and Toshihiro Itoh $^{1}$ \\ ${ }^{1}$ Graduate School of Engineering, The University of Tokyo, 7-3-1 Hongo, Bunkyo-ku, Tokyo 113-8654, Japan \\ ${ }^{2}$ Sensing System Research Center, National Institute of Advanced Science and Technology, \\ 1-2-1 Namiki, Tsukuba-shi, Ibaraki 305-8564, Japan
}

(Received May 29, 2020; accepted October 8, 2020)

Keywords: e-textile, flexible, large area, fabric, lighting

We have developed a meter-scale extremely large area LED-embedded soft fabric for threedimensional complicated shapes such as furniture, tents, and ceilings by transforming the shape of a lighting fabric. The developed meter-scale large-area LED-embedded fabric was assembled by a process in which LED-mounted $5 \times 20 \mathrm{~mm}$ pieces of printed circuit board (PCB) were first soldered to a 2-cm-wide ribbon with copper power lines, then the resultant ribbons were woven as wefts by using a 1.2 -m-wide automatic weaving machine. Fabrication with automatic weaving can produce a large $(1.2 \mathrm{~m} \times 1.2 \mathrm{~m})$, lightweight $\left(0.224 \mathrm{~kg} / \mathrm{m}^{2}\right)$ LED lighting fabric. The mechanical flexural rigidity of the LED fabric was investigated by comparing it with conventional flexible PCBs. The resultant bending stiffness of the LED fabric was 7.92 $\times 10^{-5} \mathrm{Nm}^{2} / \mathrm{m}$, which is smaller than that of PCBs, allowing the fabric to be bent easily. The hysteresis width of the bending stiffness of the LED fabric was $8.03 \times 10^{-3} \mathrm{Nm} / \mathrm{m}$, which is larger than that of PCBs, meaning that the fabric can keep its shape under bending. Finally, we demonstrated the illumination of rooms and gardens using the LED-implemented fabric by installing it on ceilings and tents with three-dimensional complicated curved shapes.

\section{Introduction}

In this study, a mechanically soft and conformable LED-implemented fabric, in which small LED-mounted printed circuit boards (PCBs) are soldered to ribbons with power lines and the resultant ribbons are woven as wefts, has been developed for lighting devices for threedimensional complicated shapes such as furniture, tents, and ceilings. These highly flexible, lightweight, and large-area lighting devices have attracted much attention because they provide the advantages of freedom of installation design in rooms ${ }^{(1,2)}$ and safety in the case of earthquakes. ${ }^{(3-7)}$ The high flexibility and conformability of the lighting devices enable them to be installed on the three-dimensional complicated surfaces of walls, furniture, or ceilings. ${ }^{(8,9)}$ Moreover, the lightweight lighting devices are safe when earthquakes occur, during which heavy lighting devices may break and drop, injuring the people underneath, which occurred

*Corresponding author: e-mail: takamatsu@pe.t.u-tokyo.ac.jp

https://doi.org/10.18494/SAM.2021.2951 
during the huge Tohoku earthquake in Japan in 2011. ${ }^{(10,11)}$ In addition, meter-scale large-area lighting devices can be applied to cover a whole ceiling or surfaces of furniture because the area of conventional home and office rooms is several square meters and conventional fluorescent light tubes are $1.4 \mathrm{~m}$ long. ${ }^{(12-14)}$

Previous studies on flexible lighting devices, including LEDs on flexible $\mathrm{PCBs}^{(15)}$ and organic LEDs on plastic substrates, ${ }^{(16,17)}$ have shown the bending of devices two-dimensionally (i.e., rolling the device on a cylinder), but they cannot be bent three-dimensionally to cover the complicated shape of furniture and equipment in rooms because of the high mechanical rigidity of the plastic substrate. Conventional plastic sheet substrates, including polyester films and polyimide films, have high mechanical rigidity and stiffness. ${ }^{(16,18,19)}$ The high rigidity means that bending the plastic substrate into a three-dimensional shape requires a large bending force. On the other hand, the high stiffness causes the plastic substrate to transform back to its original shape after it has been bent. ${ }^{(16,18)}$ Therefore, a new flexible lighting device with low mechanical rigidity needs to be developed. In our previous study, a fabric-based lighting device, in which LED-mounted PCB tapes are woven in the fabric as wefts, ${ }^{(9)}$ was developed, but there was a problem of high mechanical rigidity in the direction of the wefts because the fabric contained 5-mm-wide flexible PCB tapes as wefts. Thus, to achieve higher three-dimensional flexibility of lighting devices, in this paper, we propose a new LED-implemented fabric in which small LED-mounted PCBs are soldered to ribbons with power lines, and the resultant ribbons are woven into wefts [Fig. 1(a)]. In this new structure, the plastic substrate is used only on a small area of the PCB pieces, and most of the area is made of a textile, which increases the flexibility of the LED fabric. To compose this fabric, we developed a reel-to-reel LED ribbon assembly system $^{(20)}$ and an automatic ribbon looming system. Then, the mechanical rigidity of

(a)

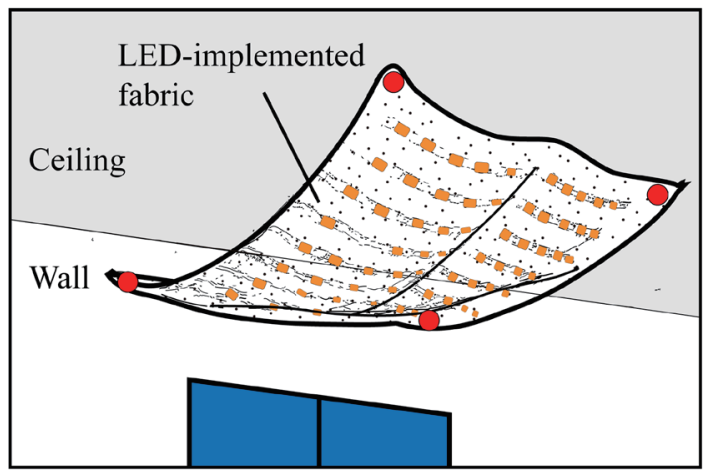

(b)

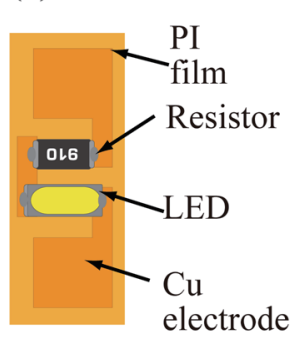

(d) (c)

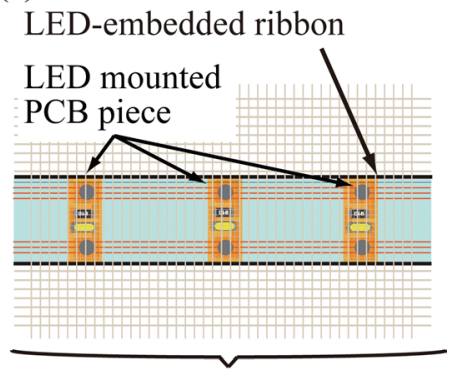

Polyester fibers

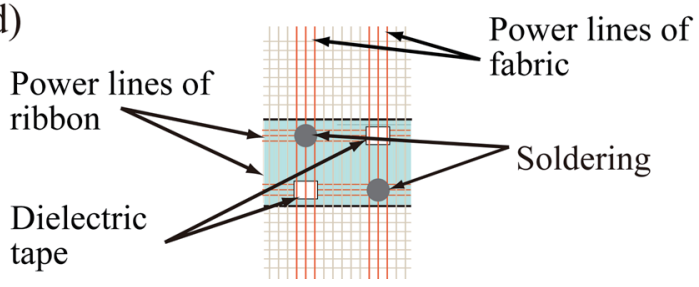

Fig. 1. (Color online) (a) Schematic view of meter-scale LED-embedded fabric for light devices to cover ceilings. The LED fabric structure is a 1.2-m-wide woven fabric that has 5-mm-wide LED-mounted PCB tapes as the wefts. (b) LED-mounted PCBs. (c) Power lines for LED tapes. (d) LEDs and resistors mounted on PCB tapes. 
the woven LED fabric was investigated and compared with that of conventional flexible PCBs. The basic characteristics of the fabric, including the size, weight, and lighting illuminance, were also measured, and then we demonstrated the illumination of a room using the LED fabric by transforming it into three-dimensional curved shapes and placing it on the ceiling.

\section{Configuration of LED-implemented Fabric}

Figures 1(a)-1(d) show our proposed LED-implemented fabric, in which small pieces of LED-mounted PCBs were mounted and soldered to ribbons with the copper wires of power lines using a small chip mounter [Fig. 2(a)], and the resultant ribbons were woven as the wefts with a pitch of $5 \mathrm{~cm}$ by using a 1.2-m-wide large automatic looming machine [Fig. 2(b)]. The detailed structure of the fabric is as follows.

A 2-cm-wide ribbon consists of 125 - $\mu \mathrm{m}$-diameter polyester fibers and 0.2 -mm-diameter copper wires [Fig. 1(c)]. Most of the area is covered with polyester fibers, and five copper wires are placed on either side of the ribbon to form power lines for the LED-mounted PCBs. Figure 1(b) shows the LED-mounted PCBs, which are composed of $5 \mathrm{~mm} \times 20 \mathrm{~mm} \times 80 \mu \mathrm{m}$ flexible PCBs, LEDs, and resistors. The copper electrodes on the PCBs have $5 \mathrm{~mm} \times 5 \mathrm{~mm}$ pads, the wiring of the LED, and a resistor. We used Nichia NSSW157AT LEDs, which have a voltage drop of $3 \mathrm{~V}$ and a rated current of $74 \mathrm{~mA}$. The resistor used for tuning the current to the LEDs was $27 \Omega$ since the supply voltage to the LEDs and resistor circuit was $5 \mathrm{~V}$. The power

(a)
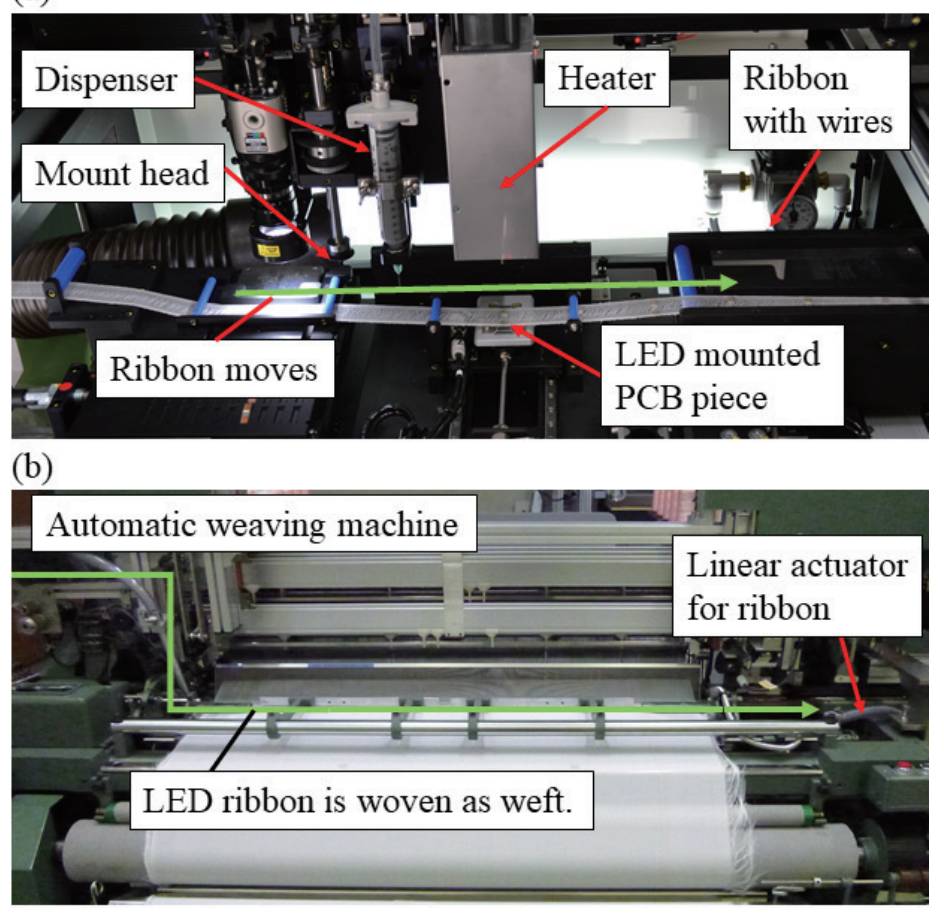

Fig. 2. (a) Reel-to-reel assembly system of LED-embedded ribbon. (b) Automatic looming machine for weaving the resultant ribbon. 
consumption of the LEDs was $0.3 \mathrm{~W}$, and a series of 100 LEDs was woven into a $1.2 \mathrm{~m} \times 1.2$ $\mathrm{m}$ piece of fabric, resulting in a total electricity consumption of $30 \mathrm{~W}$. This LED-implemented fabric provides the same light intensity as a $60 \mathrm{~W}$ standard fluorescent light tube. The ribbons and PCB pieces were connected by soldering with a pitch of $10 \mathrm{~cm}$.

The fabricated ribbons were woven as wefts with a pitch of $10 \mathrm{~cm}$ by using a $1.2-\mathrm{m}$-wide automatic looming machine. Most of the $1.2 \mathrm{~m}$ warps in the looming machine were $125-\mu \mathrm{m}-$ diameter polyester fibers, while two copper power lines were placed $2 \mathrm{~cm}$ apart on the left side of the warps. The power lines of the ribbon and those of the fabric were connected by soldering after the automatic looming.

\section{Assembly Process of LED-implemented Fabric}

In the assembly system, which is shown in Fig. 2(a), winding machines (Hashizume Laboratory) are located on either side of a small chip mounter (Okuhara Electric, SMT-64RH compact mounter) while the mounter picks up and places the PCB pieces at the stage, solder dispenser, and air reflow heater. After the PCB pieces are placed on the stage of the mounter and solder paste is dispensed on their pads, the stage is moved under the ribbon and then upward to push the PCB pieces onto the ribbon to ensure a strong connection between the PCB pieces and the ribbon. Figure 2(b) shows the automatic looming machine with two rapiers used to weave not only polyester fibers but also LED ribbons. The rapier of the LED ribbons is a linear actuator that is located on the right side of the automatic looming machine. It grasps and weaves the ribbon between the open spaces between the warps, and then the ribbon is cut and is fixed to the warps.

Figure 3 shows the LED-implemented assembly process, which consists of a reel-to-reel assembly and automatic weaving of the LED-embedded ribbons. The details of the assembly process are as follows:

(1) 20-mm-wide ribbons were woven with polyester fibers and copper wires. The copper power lines were placed on either side of the ribbons.

(2) The LED-mounted flexible PCBs were continuously mounted and soldered onto the ribbon with copper power lines. After a ribbon was moved by the specific pitch of these PCB pieces, the PCB pieces were picked up and soldered onto the desired place on the ribbon by using an LED ribbon assembly machine, which was described in our previous work. ${ }^{(15)}$ The same procedure was repeated to form tens of meter-long LED-embedded ribbons.

(3) Polyester fibers $(125 \mu \mathrm{m}$ diameter) and two copper wires were set in the 1.2-m-wide automatic looming machine as warps. The two copper wires used as the power lines of the LED-embedded ribbon were located on the left side. The polyester fibers were interlaced into the warps.

(4) The LED-embedded ribbons were interlaced with a linear actuator with a $10 \mathrm{~cm}$ pitch. The same process consisting of weaving polyester fibers and inserting LED ribbons was repeated to make tens of meter-long fabrics.

(5) The copper power lines in the LED ribbons were soldered to the woven copper power lines in the fabric to supply electricity to the LEDs. 
(1)

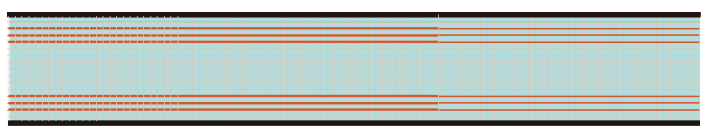

(2)

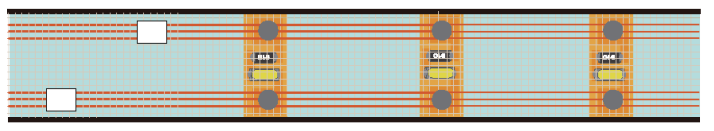

(3)

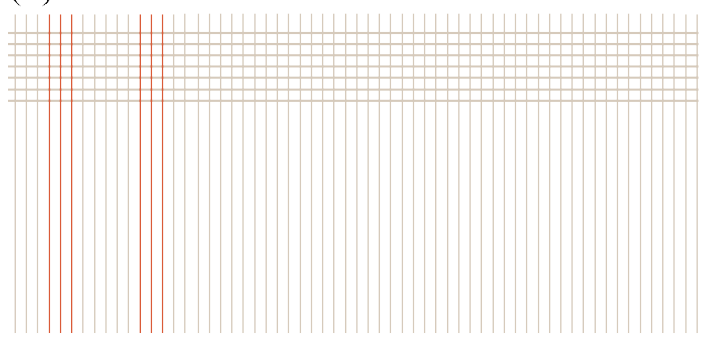

(4)

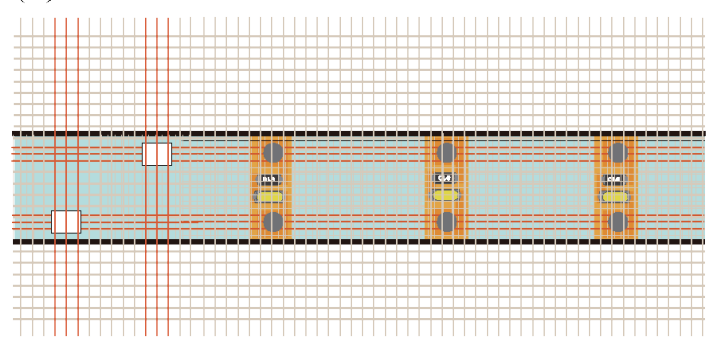

(5)

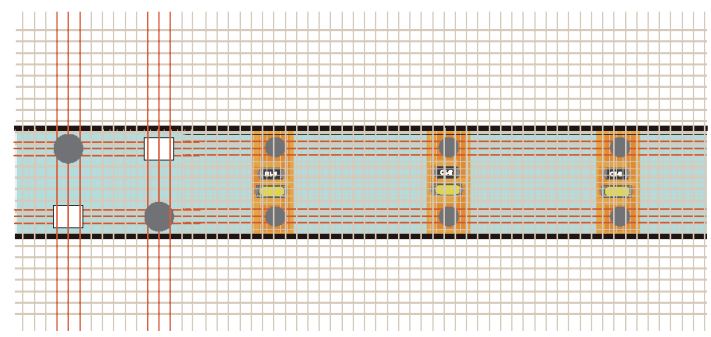

Fig. 3. (Color online) LED-implemented fabric assembly process. (1) Weaving of $2 \mathrm{~cm}$ ribbon. (2) Reel-toreel mounting and soldering of LED-mounted PCBs on ribbon. (3) Polyester fiber weaving. (4) Weaving of LEDmounted ribbons as wefts. (5) Connecting power lines of fabric with power lines of LED ribbon.

Figure 4(a) shows the $1.2 \mathrm{~m} \times 1.2 \mathrm{~m}$ LED-implemented fabric woven with our ribbon assembly machine and automatic looming machine. Figures 4(b) and 4(c) show the LEDmounted ribbon woven fabric and the connection between the power lines of the LED ribbon and those of the fabric, respectively. The meter-scale size of the LED-implemented fabric makes it suitable for furniture or ceilings because the area of a conventional office is several square meters. The weight of the fabric is only $0.224 \mathrm{~kg} / \mathrm{m}^{2}$, which is much lighter than that of a typical plaster or concrete ceiling board $\left(6-15 \mathrm{~kg} / \mathrm{m}^{2}\right)$, so the fabric will not cause serious injury even if it drops on people as a result of a large earthquake. The mounting duration of a single LED chip was $70 \mathrm{~s}$ including dispensing, mounting, and hot-air heating. Even in a normal reflow oven, mounting takes more than $180 \mathrm{~s}$, so there is no productivity problem. It takes about 164 min to make the 140 pieces required for a $1.2 \mathrm{~m} \times 1.2 \mathrm{~m}$ LED-implemented fabric. To increase the speed of production, it is possible to shorten the mounting time by using a modified hotair heating system. It takes about 20 min per meter to weave the LED-implemented fabric. The weaving duration is the same as that of an ordinary rapier-type automatic looming machine.

\section{Mechanical Characteristics of Fabricated Device}

To set the LED fabric on the three-dimensional surfaces of complicated shapes, the fabric should have specific mechanical properties: high softness so that the fabric can be bent with low bending force and high conformability so that the fabric can keep its shape. To characterize these mechanical features of the LED fabric, a mechanical flexural rigidity test, where the bending moment was measured by changing the bending curvature, was performed. To compare 


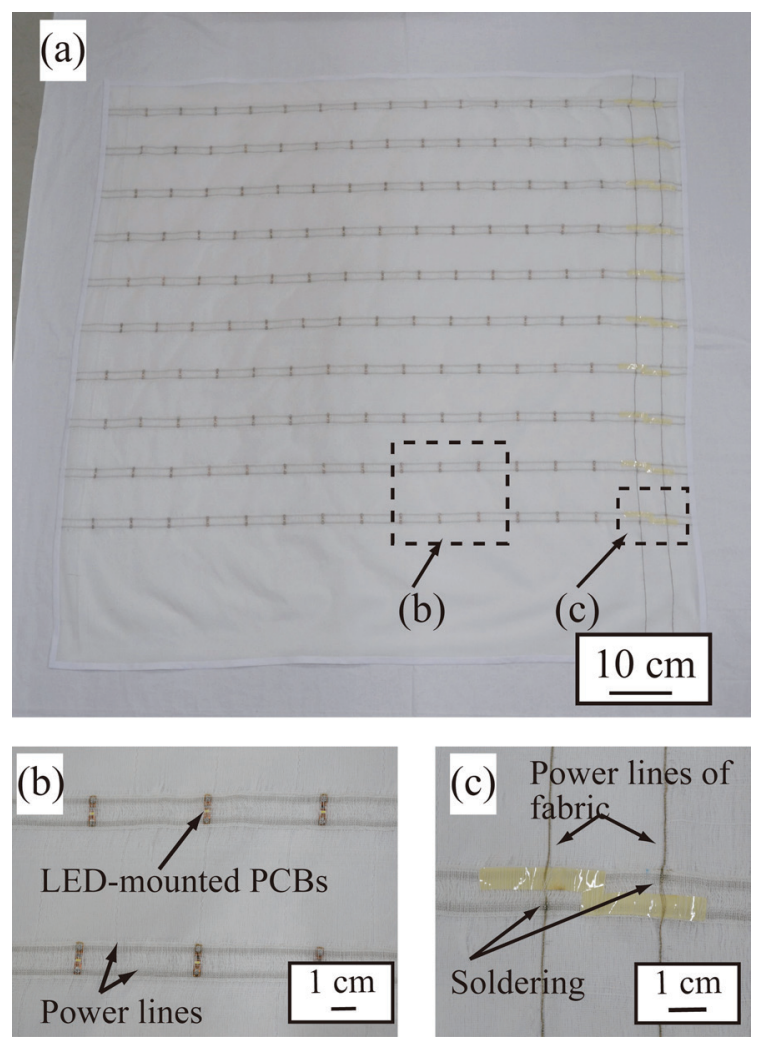

Fig. 4. (Color online) (a) Overall photograph of $1.2 \mathrm{~m} \times 1.2 \mathrm{~m}$ LED-implemented fabric. (b) LED ribbon in the fabric. (c) Power lines and dielectric tape of LED-implanted fabric.

our fabric with conventional flexible PCBs, a PCB mechanical flexural rigidity test was also performed by using a pure bending test apparatus as shown in Fig. 5. A bending test of an LEDimplemented fabric and a flexible substrate of $2 \mathrm{~cm}$ width and $10 \mathrm{~cm}$ height was conducted using a pure bending tester (KATOTECH, KES-FB2-AUTO-A) consisting of a rotary actuator and a torque sensor. Samples were mounted on the pure bending tester, and the bending moment was measured while changing the curvature. The bending moment per unit length is the bending moment normalized by the sample height. Figure 6 shows the obtained relationship between bending curvature and bending moment. Figures 6(a) and 6(b) show the relationship for the LED fabric and that for the flexible PCBs, respectively. From these relationships, the softness and conformability are expressed. Firstly, the softness is equal to bending stiffnessB, which is defined by the average slope of the linear region of the bending hysteresis curve between radii of curvature of 50 and $150 \mathrm{~m}^{-1}$. The average stiffnesses of the fabric and the flexible PCBs are $7.92 \times 10^{-5}$ and $13.43 \times 10^{-5} \mathrm{Nm}^{2} / \mathrm{m}$, respectively, which shows that the average stiffness of the fabric is smaller than that of the flexible PCBs (Table 1). Therefore, the fabric is softer than conventional flexible PCBs because if the stiffness is large, a large bending moment is needed to increase the curvature. Secondly, the conformability of the fabric is the bending hysteresis $2 \mathrm{HB}$, which is defined as the average width of the bending hysteresis loop at $\pm 50 \mathrm{~m}^{-1}$ curvature. The $2 \mathrm{HB}$ values of the fabric and flexible PCBs are $8.03 \times 10^{-3}$ and 2.36 


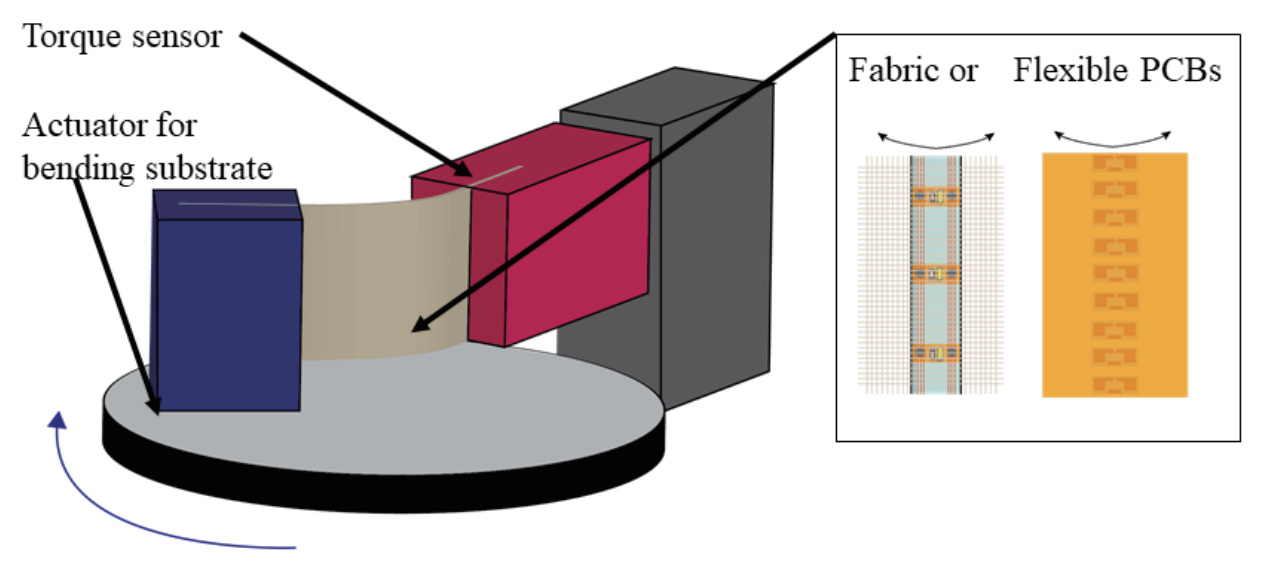

Fig. 5. (Color online) Pure bending test apparatus.

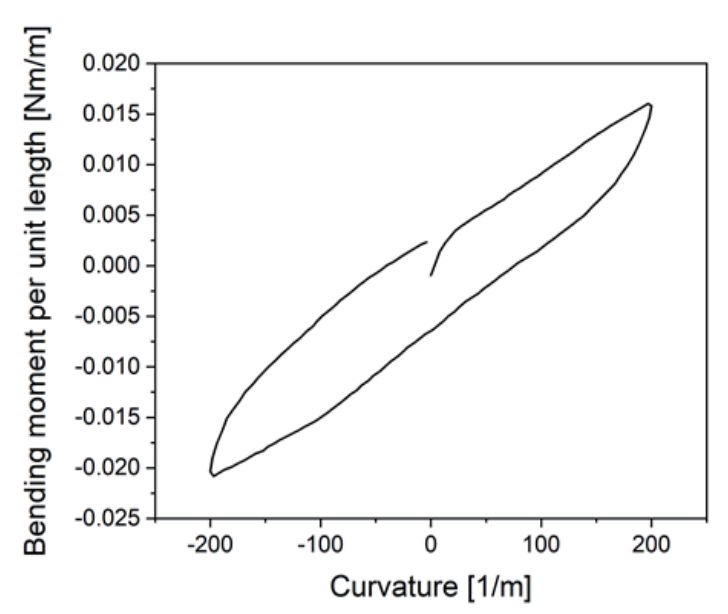

(a)

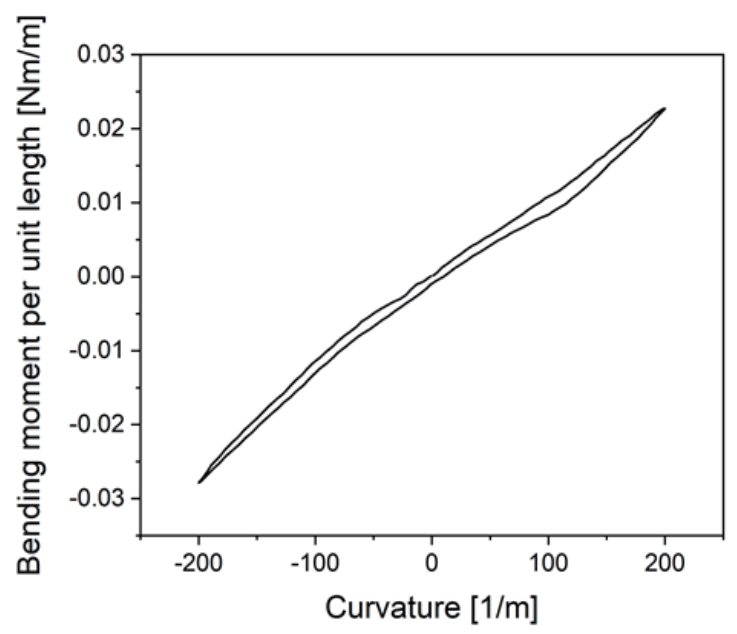

(b)

Fig. 6. (a) Relationship between bending curvature and resultant bending moment per unit of the LEDimplemented fabric. (b) Relationship between bending curvature and resultant bending moment per unit of flexible PCBs.

Table 1

Mechanical bending stiffness and bending hysteresis widths of LED-implemented fabric and conventional flexible PCBs.

\begin{tabular}{lccccccc}
\hline \multirow{2}{*}{ Material } & \multicolumn{2}{c}{ Bending stiffness B $\left(\mathrm{N} \cdot \mathrm{m}^{2} / \mathrm{m}\right)$} & & \multicolumn{2}{c}{ Bending hysteresis width $2 \mathrm{HB}(\mathrm{Nm} / \mathrm{m})$} \\
\cline { 2 - 4 } \cline { 6 - 8 } & + & - & Ave. & & + & - & Ave. \\
\hline LED fabric & $8.53 \times 10^{-5}$ & $7.32 \times 10^{-5}$ & $7.92 \times 10^{-5}$ & & $7.44 \times 10^{-3}$ & $8.63 \times 10^{-3}$ & $8.03 \times 10^{-3}$ \\
\hline Flexible PCBs & $12.86 \times 10^{-5}$ & $14.01 \times 10^{-5}$ & $13.43 \times 10^{-5}$ & & $2.44 \times 10^{-3}$ & $2.29 \times 10^{-3}$ & $2.36 \times 10^{-3}$ \\
\hline
\end{tabular}

$\times 10^{-3} \mathrm{Nm} / \mathrm{m}$, respectively (Table 1 ). Thus, the $2 \mathrm{HB}$ value of the fabric is larger than that of the flexible PCBs. When the fabric or flexible PCBs are bent back to the original shape, the bending moment of the fabric is smaller than that of the flexible PCBs, which means that the fabric is highly conformable compared with conventional flexible PCBs because the bendingback force is small and the fabric retains its shape after bending. 


\section{Lighting Characteristics and Lighting Demonstration of LED-implemented Fabric after Transforming It into Three-dimensional Complicated Shape}

The lighting characteristics of the fabricated LED-implemented fabric were evaluated by measuring its light intensity, and the illumination of rooms was demonstrated by transforming the fabric into a three-dimensional curved shape and placing it on the ceiling.

The luminance of the LED-implemented fabric with a $1.2 \mathrm{~m} \times 1.2 \mathrm{~m}$ area was characterized in accordance with the lighting standards of Japan Industrial Standard (JIS) Z 9110. The luminances at distances of 1.0 and $0.3 \mathrm{~m}$ from the LED fabric were measured with a lux meter (HIOKI 3423 Lux HiTester), and the results are shown in Table 2. The LED fabric with 100 LEDs provides $212 \mathrm{~lx}$ at $1.0 \mathrm{~m}$ from the tape. Since the JIS states that a light intensity of more than 200 lx is required for usual work in an office, our LED fabric meets this criterion. Thus, our LED fabric can be used for lighting rooms in offices and homes.

Finally, the $1.2 \mathrm{~m} \times 1.2 \mathrm{~m}$ LED-implemented fabric was used to illuminate rooms and gardens by transforming it into a three-dimensional curved ceiling and tent, as shown in Figs. 7(a) and 7(b), respectively. The close-up photo in Fig. 7(b) shows the LEDs arrayed on the fabric composed of meter-scale lighting devices. The LED fabric was transformed into the shape of an escallop shell and placed on the ceiling and tent. Therefore, the LED-implemented fabric is conformable and thus is suitable for three-dimensional shape applications.

Table 2

Luminance of LED-implemented fabric.

\begin{tabular}{lc}
\hline Distance from the LED fabric & Luminance (lx) \\
\hline $30 \mathrm{~cm}$ & 775 \\
$1 \mathrm{~m}$ & 212 \\
\hline
\end{tabular}

(a)

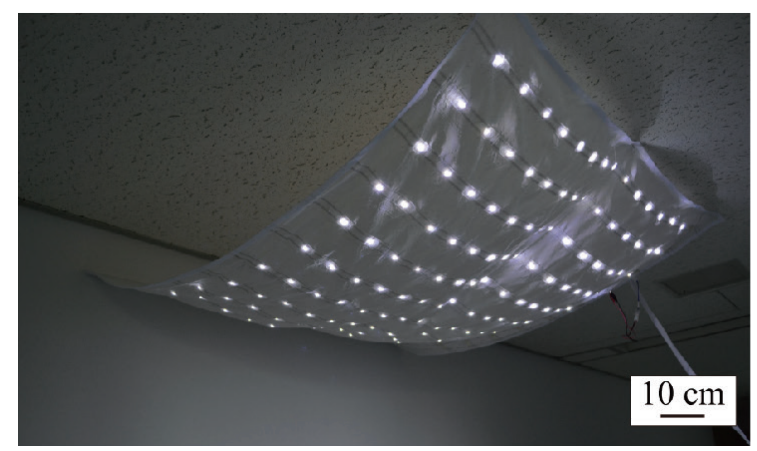

(b)

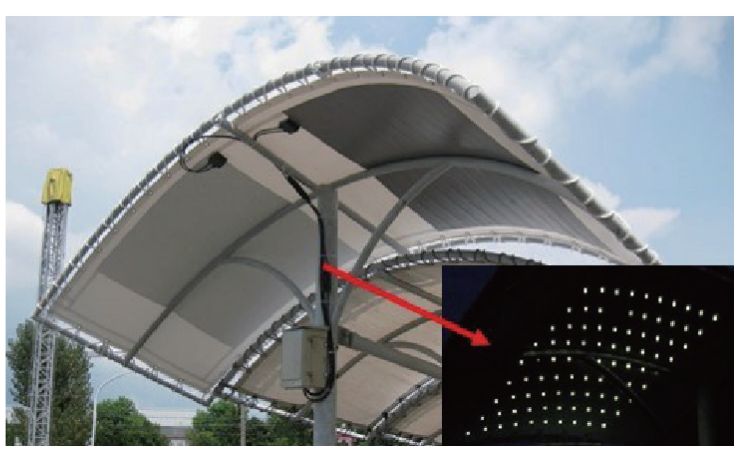

Fig. 7. (a) Lighting demonstration of LED-implemented fabric ceiling by transforming it into the threedimensional shape of an escallop shell and placing it on the ceiling. (b) Lighting demonstration of LEDimplemented tensile membrane structure. 


\section{Conclusions}

An LED-implemented fabric, in which small PCB pieces with LEDs are mounted on ribbons and the ribbons are woven as wefts, was proposed and assembled to achieve a mechanically soft and conformable lighting device for applications to three-dimensionally complicated surfaces, such as furniture, tents, and ceilings. The results of our study are as follows:

1. The proposed structure of the LED-implemented fabric comprises LED-mounted $5 \mathrm{~mm} \times 2$ $\mathrm{cm}$ pieces of PCBs soldered to 2-cm-wide ribbons with copper power lines, and the resultant ribbons are woven as wefts, forming a 1.2-m-wide LED fabric. Since most of the area of the lighting device is a flexible fabric instead of rigid PCBs, the LED fabric has high flexibility.

2. The developed weaving assembly system for the LED fabric with a 1.2-m-wide automatic looming machine can produce a large $(1.2 \mathrm{~m} \times 1.2 \mathrm{~m})$ LED lighting fabric that is lightweight $\left(0.224 \mathrm{~kg} / \mathrm{m}^{2}\right)$.

3. The LED fabric is soft compared with conventional flexible PCBs because the stiffness of the LED fabric is $7.92 \times 10^{-5} \mathrm{Nm} / \mathrm{m}^{2}$, which is smaller than that of PCBs. On the other hand, the LED fabric is conformable compared with PCBs because the bending hysteresis of the fabric is $8.03 \times 10^{-3} \mathrm{Nm} / \mathrm{m}$, which is larger than that of flexible PCBs.

4. At a distance of $1.0 \mathrm{~m}$, the luminance of the LED fabric is $212 \mathrm{~lx}$, which is the luminance of conventional workplaces at factories and offices. We demonstrated the illumination of rooms and gardens by transforming the LED fabric into the three-dimensional shape of an escallop shell and placing it on a ceiling and tent.

Our LED-implemented fabric and assembly technology will lead to highly shapeconfigurable lighting applications for fabric ceilings, walls, tensile membrane structures, and other large areas in buildings.

\section{Acknowledgments}

This work was partially supported by the New Energy and Industrial Technology Development Organization (NEDO) and JSPS KAKENHI Grant Number JP19H04147.

\section{References}

1 M. Stoppa and A. Chiolerio: Sensors 14 (2014) 11957. https://doi.org/10.3390/s140711957

2 K. Cherenack and L. Pieterson: J. Appl. Phys. 112 (2012) 091301. https://doi.org/10.1063/1.4742728

3 B. Bridgensa and M. Birchall: Eng. Struct. 44 (2012) 1. https://doi.org/10.1016/j.engstruct.2012.05.044

4 H. Berger: Eng. Struct. 21 (1999) 669. https://doi.org/10.1016/S0141-0296(98)00022-4

5 K. U. Bletzinger and E. Ramm: Comput. Struct. 79 (2001) 2053. https://doi.org/10.1016/S0045-7949(01)000529

6 Taiyo Kogyo Co. Ltd.: http://www.taiyokogyo.co.jp/maku tenjyo/ (accessed 1 July 2015).

7 Normalu Barrisol SAS: http://en.barrisol.com/products-ceilings.htm (accessed 1 July 2015).

8 P. Harold: Philips Research Password 28 (2006) 6.

9 S. Takamatsu, T. Yamashita, and T. Itoh: Microsyst. Technol. 21 (2014) 1209. https://doi.org/10.1007/s00542$014-2174-\mathrm{z}$

10 M. Motosaka and K. Mitsuji: Soils Found. 52 (2012) 929. https://doi.org/10.1016/j.sandf.2012.11.012

11 G. Magliulo, V. Pentangelo, G. Maddaloni, V. Capozzi, C. Petrone, P. Lopez, R. Talamonti, and G. Manfredi: Bull. Earthq. Eng. 10 (2012) 1819. https://doi.org/10.1007/s10518-012-9383-6 
12 Y. S. Chan and S. Lee: J. Semicond. 32 (2011) 014005. https://doi.org/10.1088/1674-4926/32/1/014005

13 M. Ayob and G. Kendall: Eur. J. Oper. Res. 186 (2008) 893. https://doi.org/10.1016/j.ejor.2007.03.042

14 M. Ayob and G. Kendall: J. Syst. Sci. 40 (2009) 553. https://doi.org/10.1080/00207720902777964

15 S. Takamatsu, T. Yamashita, and T. Itoh: Microsyst. Technol. 20 (2013) 2247. https://doi.org/10.1007/s00542$\underline{013-1925-6}$

16 C.J. Chiang, C. Winscom, S. Bull, and A. Monkman: Org. Electron. 10 (2009) 1268. https://doi.org/10.1016/ j.orgel.2009.07.003

17 J. H. Jou, S. Kumar, A. Agrawal, T. H. Li, and S. Sahoo: J. Mater. Chem. C 3 (2015) 2974. https://doi. org $/ 10.1039 / \mathrm{C} 4 \mathrm{TC} 02495 \mathrm{H}$

18 N. Akamatsu, W. Tashiro, K. Saito, J. Mamiya, M. Kinoshita, I. Ikeda, J. Takeya, S. Fujikawa, A. Priimagi, and A. Shishido: Sci. Rep. 4 (2014) 5377. https://doi.org/10.1038/srep05377

19 J. Lewis: Mater. Today 9 (2006) 38. https://doi.org/10.1016/S1369-7021(06)71446-8

20 S. Takamatsu, T. Yamashita, T. Murakami, A. Masuda, and T. Itoh: Microsyst. Technol. 22 (2015) 1079. https:// doi.org/10.1007/s00542-015-2467-x 